\title{
Management of glucocorticoids-induced osteoporosis: role of teriparatide
}

\author{
Silvia Migliaccio' \\ Marina Brama' \\ Nazzarena Malavolta ${ }^{2}$ \\ 'Dipartimento di Fisiopatologia \\ Medica, Policlinico Umberto I, \\ Università degli Studi Sapienza di \\ Roma, Italy; ${ }^{2}$ Dipartimento di Medicina \\ Interna, Policlinico S Orsola Malpighi, \\ Bologna, Italy
}

\begin{abstract}
Glucocorticoids (GC)-induced osteoporosis (GIOP) is the most common cause of secondary osteoporosis, which leads to an increased fracture risk in patients. The normal bone turnover depends on a balance between osteoblasts and osteoclasts activity and GC can cause a rapid bone loss, decreasing bone formation and increasing bone resorption. The decreased bone formation is mainly due to the GC-induced apoptosis of both osteoblasts and osteocytes, while the increased bone resorption is due to the increased life-span of pre-existing osteoclasts. Bisphosphonates are clearly effective in preventing and treating GIOP but anabolic therapeutic strategies are the new promising therapeutic alternative. Experimental and clinical studies indicate that teriparatide, the active (1-34) parathyroid hormone (PTH) molecule, is efficacious for the treatment of GIOP, being able to induce an increase in bone mass in these patients. Intermittent administration of human PTH (1-34) stimulates bone formation by increasing osteoblast number. Additionally, human PTH (1-34) modulates the level and/or activity of locally produced growth factors and cytokines. Teriparatide has been demonstrated in several clinical studies to significantly decrease the incidence of fractures in patients affected by GIOP. It has recently received an indication for GIOP and its label indication has also been expanded.
\end{abstract}

Keywords: glucocorticoids, osteoblasts, osteoclasts, osteoporosis, teriparatide

\section{Introduction}

Early last century Cushing described the negative effect of hypercotisolism on the skeleton. ${ }^{1}$ Nowadays secondary forms, due to pharmacological use of glucocorticoids (GC), are the most frequent forms of an excess of these hormones. ${ }^{2-6}$ GC are the most widely used therapy in medicine and long-term use is characterized by a significant alteration of bone tissue, named GC-induced osteoporosis (GIOP), which is a metabolic bone disease characterized by decreased skeletal strength with an increased fracture risk. ${ }^{4}$ The GC-induced bone loss is dose-dependent, but it can also be present with long-term low dosage treatments. ${ }^{3-6}$ Indeed, the loss of bone mass occurs in a biphasic manner with a fast decrease at the beginning of therapy (loss of $12 \%$ in the first year) and a slower decrease after then $(3 \%) .{ }^{7-8}$ GIOP must be considered a serious pathological condition because of the high number of patients who use these molecules to treat many different chronic diseases. ${ }^{8}$

As first described by Cushing, GIOP affects both trabecular and cortical bone and a vertebral fracture can be the first symptom of the disease. ${ }^{1,9,10}$.

Although the clinical manifestations of GC therapy have been known since the early 20 th century, ${ }^{1-6}$ the cellular and molecular mechanisms of skeletal alterations are not yet fully known. Some data suggest that alterations in hormonal levels might play a role in the calcium-phosphorus homeostasis (Table 1); however, GC exert a direct receptor-mediated effect on bone cells, leading to an altered bone remodeling. ${ }^{11}$

Indeed, bone tissue is a metabolically active organ undergoing continuous remodeling throughout life, which serves to adjust bone architecture to meet mechanical
Correspondence: Silvia Migliaccio Dipartimento di Fisiopatologia Medica, Università Sapienza di Roma, Italy Tel +39064997072l

$\mathrm{Fax}+39064461450$

Email silvia.migliaccio@uniromal.it 
Table I Mechanisms involved in glucocorticoids (GC)-induced osteoporosis

Direct effects on bone cells

Decrease of osteoblasts proliferation and activity

Increase of osteoblast and osteocytes apoptosis

Increase of osteoclasts life-span and activity

Effects on phosphorus and calcium homeostasis

Decrease of intestinal calcium absorption

Increase of urinary calcium excretion

Effects on pituitary-gonads-adrenal axis

Decrease of pituitary gonadotrophins

Decrease of estradiol and testosterone synthesis and secretion

Inhibition of androstenedione synthesis and secretion

Effects on hormones modulating calcium-phosphorus homeostasis

Increase of PTH synthesis and secretion

Increase of PTH and Vitamin D sensitivity (hypothetical)

needs, to repair microdamage of bone matrix, and to prevent accumulation of old and damaged bone. Additionally, bone remodeling plays an important role in plasma calcium homeostasis. As noted, this process involves the removal of damaged bone tissue by osteoclasts followed by the formation of bone matrix through the osteoblasts, ${ }^{11}$ derived from a mesenchymal cell progenitor, unique for adypocites, chondrocytes and muscle cells.

The regulation of bone remodeling is known to be both systemic and local, and GC dramatically alter these sophisticated mechanisms, decreasing bone formation and increasing resorption, with a net decrease in the number and in the perimeter of the trabeculae. ${ }^{12,13}$

\section{Molecular and cellular mechanisms}

GC are steroidal hormones which act as ligand-induced transcription factors by binding intracellular receptors, which leads to conformational changes followed by nuclear translocation of hormone-bound receptor. ${ }^{14}$ These ligandinduced intracellular events lead to the induction/repression of specific target genes ${ }^{14,15}$ and specific biological effects.

Some data indicate that these hormones, as also described for estrogens, ${ }^{16}$ induce nongenomic effects by a putative membrane receptor, which activates intracellular kinases such as the extracellular signal-regulated kinases (ERKs), c-Jun N-terminal kinase (JNK), and proline rich tyrosine kinase 2 (Pyk2). ${ }^{17,18}$ Because GC receptors are present on both osteoblasts and osteoclasts, bone tissue is a target for GC. ${ }^{19,20}$ Furthermore, these steroids can induce different effects on skeletal tissue depending on their concentration, time of exposure, and cell differentiation..$^{20-25}$

The first rapid effect induced by GC exposure is a rapid bone loss due to osteoclast activation. GC can modulate osteoclast activity directly: short-term exposure to GC induces an increase in the number and activity of osteoclasts as well as a decrease in cell apoptosis and a net increase in osteoclast life-span. ${ }^{5,6,25} \mathrm{GC}$ can also modulate bone resorbing cells through an osteoblast-mediated mechanism by stimulating the synthesis of both RANKL (receptor activator for nuclear factor $\kappa \mathrm{B}$ ligand) and granulocyte colony-stimulating factor (G-CSF) and by decreasing osteoprotegerin (OPG) expression. ${ }^{26}$

Long-term GC exposure or exposure to high dosages induce further negative effects, such as osteoblast apoptosis, decreased osteoblast proliferation and differentiation, and osteocytes apoptosis, with a consequent significant decrease in bone formation..$^{27-29}$

Interestingly, low concentrations of GC stimulate both osteoblasts proliferation and differentiation by specific genes activation such as bone morphogenetic proteins (BMPs), the transcription factor $\mathrm{C} b f a-1$, transforming growth factor beta (TGF- $\beta$ ) and insulin-like growth factor I (IGF-I). However, an alteration of these mechanisms, induced by either high concentration or long-term exposure, strongly inhibits mesenchymal cells differentiation, osteoblasts proliferation and activity, and also increases both osteoblasts and osteocytes apoptosis., ${ }^{5,12,13,24-29}$ These significant changes in bone homeostasis and remodeling, as outlined in Figure 1, lead to bone loss, osteopenia and consequently an increase in fragility fracture risk.

\section{Therapeutical perspectives}

As mentioned above, because GIOP is a severe condition which leads to an increased fracture risk within the first months of therapy, ${ }^{30}$ efficacious therapies are needed to counter their deleterious effects on the skeleton. Although bisphosphonates have been demonstrated to be an efficacious therapy for both prevention and cure of GIOP,,$^{31-33}$ the new bone anabolic agent teriparatide is a highly promising and interesting molecule for the treatment of GIOP.

\section{Mechanisms of action of teriparatide}

The beneficial effects of daily injection of human parathyroid hormone (PTH) amino-terminal peptide 1-34, teriparatide, have been shown in randomized, placebo-controlled trials in postmenopausal women, and in elderly men and in women with GIOP. ${ }^{34-36}$

Osteoblasts, bone lining cells, and bone marrow stromal cells have PTH receptors, and intermittent PTH stimulates these cells through the modulation of cAMP concentrations and 


\section{Glucocorticoids}

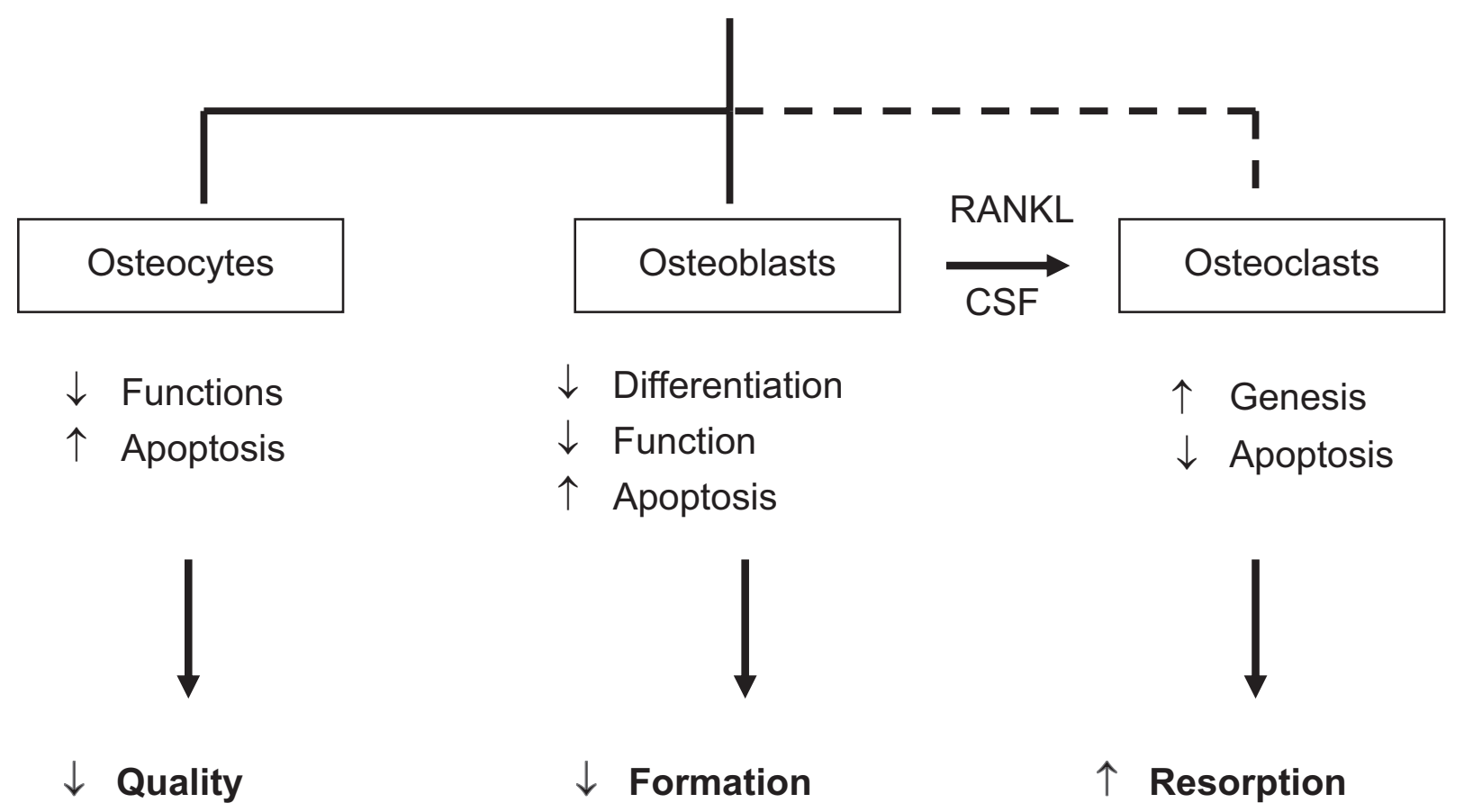

Figure I Synthesis of glucocorticoids effects on bone cells.

Abbreviation: CSF, colony-stimulating factor; RANKL, receptor activator for nuclear factor $\kappa \mathrm{B}$ ligand.

cAMP-dependent protein kinase A. ${ }^{38}$ The PTH receptor also activates the calcium protein kinase $\mathrm{C}$ pathway, stimulating proliferation of cells in the osteoblastic lineage..$^{39,40}$

The new molecule teriparatide exerts its anabolic effect at least in part by stimulating the MAPK pathway ${ }^{41}$ and, thus, modulating the differentiation, proliferation, and activity of the osteoblasts pool, ${ }^{37,41,42}$ stimulating differentiation and activation of quiescent lining cells, ${ }^{41,42}$ increasing the lifespan of osteoblasts and osteocytes by inhibiting their apoptosis. ${ }^{37,43}$

Some of these effects seem mediated by direct activation of the essential and early transcription factor Runx2, which plays a pivotal role in the osteoblasts differentiation pattern, ${ }^{44}$ likely activating a PKA-dependent increase ${ }^{37,38}$ and/or modulating the expression of cyclins and cyclin-dependent kinase inhibitors important in both pro-survival and pro-differentiating effects of PTH on cells of osteoblast lineage. ${ }^{37,45}$

Further, teriparatide exerts control of replication, differentiation and survival of osteoblasts progenitors by modulating the synthesis and release of local mediators including Wnt, BMPs, TGF- $\beta$, IGF-I, fibroblast growth factor-2 (FGF-2) and interleukin-6 (IL-6). ${ }^{37,46,47}$

Interestingly, recent data have shown that teriparatide, by these mechanisms of action, can counteract the GC-induced effects on bone cells. ${ }^{37}$
Bone levels of IGF-I decreased by GC $^{27,32}$ can be stimulated by PTH, leading to increasing pro-differentiating and pro-survival effects on osteoblats. ${ }^{37,46,47}$ More recent studies have also shown that PTH modulates both Wnt and sclerostin expression, which play important, and opposite, roles in the control of bone formation. ${ }^{37,46-48} \mathrm{PTH}$, in fact, blunts mRNA and protein expression of the secreted osteocytic factor sclerostin, ${ }^{37,46-49}$ which prevents the binding of Wnt ligands to their receptors, which comprise Frizzled complex with either LRP5 or LRP6, ${ }^{37,46,47,49,50}$ critical for bone formation. ${ }^{46}$

Additionally, GC stimulate the differentiation of stromal cells towards the adipocyte lineage, ${ }^{47,51}$ decreasing the differentiation of progenitors towards bone cell lineages and, thus, contributing to the disruption of bone cell homeostasis. . $^{37,46,51}$ Intermittent PTH inhibits PPAR $\gamma$ transactivation activity, decreasing adipocytic differentiation and leading to an increase in the number of osteoblasts ${ }^{37,46,51}$ and again antagonizing the deleterious effects of these steroids on the skeleton.

\section{Clinical implications of teriparatide in GIOP}

Prophylaxis in patients receiving GC is extremely low. Recently published studies estimate that the proportion of patients receiving some form of osteoporosis prophylaxis is 
between $30 \%$ and $62 \% .{ }^{51}$ The use of bone active medication is extremely low among GC users with estimates of just $1.8 \%$ of patients using bisphosphonates during the period of follow-up. ${ }^{52}$

Current guidelines for GIOP management recommend bisphosphonates, especially alendronate and risedronate, as first-line agents for GIOP, and guidelines propose the preventive use of bisphosphonates early in the course of GC therapy in high-risk patients. ${ }^{53,54}$

More recently, efficacy data have demonstrated that teriparatide is an efficacious treatment for patients with GIOP compared with an approved treatment, alendronate. ${ }^{58-61}$ Due to the results obtained in these clinical studies, teriparatide has recently received an indication for GIOP and label indication has also been expanded.

Indeed, it is clear from the mechanisms of actions described above that teriparatide is, to date, the only anabolic molecule that can counteract the deleterious effects of $\mathrm{GC}$ on the skeleton, and thus is an efficacious therapy for GIOP. ${ }^{57}$

The first interesting data on the protective role of teriparatide in GIOP have been published by Lane and colleagues, who showed, in a small pilot study, that teriparatide could not only block the GC-induced bone loss, but could even increase spine bone mineral density (BMD) by $12 \%$ and femoral neck BMD by a slightly lesser amount. $^{58,59}$

Interestingly, the same authors measured BMD of the spine every 6 months by dual-energy X-ray absorptiometry (DXA) and L1 and L2 vertebrae by quantitative computed tomography (QCT) annually. Vertebral cross-sectional area (VCSA) was obtained from the QCT scans and the vertebral compressive strength VCSA was also calculated. After 1 year of human PTH (1-34) treatment, VCSA significantly increased and this result was maintained after treatment was discontinued. Since vertebral fracture risk is related to both bone size and bone mass, the authors speculated that the increase in vertebral size associated with human PTH (1-34) treatment was, at least in part, responsible for increased vertebral bone strength and reduction of fracture risk. ${ }^{59}$

A larger study by Saag and colleagues further demonstrated the efficacy of teriparatide in GIOP. ${ }^{60-61}$ The data were derived from an 18-month randomized, double-blind controlled trial, in which teriparatide was given to women and men with osteoporosis (age 22-89 years) who had received GC for at least 3 months (prednisone equivalent, $5 \mathrm{mg}$ daily or more) and compared with alendronate. The primary outcome was the change in BMD at the lumbar spine, while secondary outcomes included changes in hip BMD, markers of bone turnover, incidence of fractures and safety. The data showed that teriparatide blocked, as already demonstrated, the bone loss induced by GC, but also induced a significant increase in $\mathrm{BMD}$ at the lumbar spine $(7.2 \% \pm 0.7 \%)$ by 6 months $(p<0.001)$. Even more interestingly, fewer new vertebral fractures were present in the teriparatide group than in the alendronate group $(0.6 \%$ vs $6.1 \%, \mathrm{p}=0.004)$ while the incidence of nonvertebral fractures was similar in the two groups $(5.6 \%$ vs $3.7 \%, \mathrm{p}=0.36) .{ }^{60,61} \mathrm{In}$ following studies, ${ }^{62}$ serum levels of RANKL, OPG, IL-6, and IL-6sR were evaluated at baseline and thereafter for a total of 24 months. Teriparatide caused a rapid and significant increase in serum RANKL within 1 month, remaining elevated throughout the duration of therapy. IL-6 increased significantly within 1 month, but returned to baseline levels more rapidly. In contrast, OPG was mildly suppressed from 6 months after therapy. ${ }^{62}$ These data further support the hypothesis that human PTH (1-34) first stimulates osteoblast maturation and function, which in turn leads to osteoclast activation with a consequent gradual rebalancing of bone formation and resorption. The bone mass increase in specific sites might require different lengths of time, as demonstrated in another study which showed maximum increase in bone mass at the hip at least 6 to 12 months after the PTH treatment discontinuation. ${ }^{63}$

The 36-month data, an extension of this published study, was presented at the 2008 meeting of the America Society of Bone and Mineral Research at Montreal, confirming the increase in BMD, the persistence of the significant decrease in fracture risk and, also, the safety of this therapy. ${ }^{64}$ In particular, in this 36-month trial GIOP patients treated with teriparatide had greater increases in BMD at the lumbar spine and femoral neck and fewer new vertebral fractures compared with patients treated with alendronate. Furthermore, teriparatide treatment, usually prescribed for 24 months, was well tolerated in the 36-month trial.

In conclusion, the mechanism of action of this new anabolic agent and the clinical data demonstrate that teriparatide can be considered a safe and highly promising therapeutic approach for GIOP.

\section{Acknowledgments}

Authors would like to thank Dr Libuse Tauchmanova for helpful discussion.

\section{Disclosures}

None of the authors disclose conflicts of interest. 


\section{References}

1. Cushing H. The basophil adenomas of the pituitary body and their clinical manifestations (pituitary basophilism). Bull Johns Hopkins Hosp. 1932;50:137-195.

2. Lukert, B. Glucocorticoid-induced osteoporosis. In: Marcus R, Feldman D, Kelsey J, editors. Osteoporosis. Academic Press, San Diego, CA, 1996;801-820.

3. Fitzpatrick LA. Glucocorticoid-induced osteoporosis. In: Marcus R (ed) Osteoporosis. Blackwell Scientific Publications, Boston, MA, 1994 p. 202-226.

4. NIH Consensus Development Panel on Osteoporosis prevention, diagnosis, and therapy. Osteoporosis prevention, diagnosis, and therapy. JAMA. 2001;285:785-95.

5. Weinstein RS. Glucocorticoid-induced osteoporosis. Rev Endocr Metab Disord. 2001;2:65-73.

6. Lukert BP, Raisz LG. Glucocorticoid-induced osteoporosis: pathogenesis and treatment. Ann Intern Med. 1990;112:344-346.

7. LoCascio V, Bonucci E, Imbimbo B, et al. Bone loss in response to long-term glucocorticoid therapy. Bone Miner. 1990;8:39-51.

8. Steinbuch M, Youket TE, Cohen S. Oral glucocorticoid use is associated with an increased risk of fracture. Osteoporos Int. 2004;15:323-328.

9. Dempster D. Bone histomorphometry in glucocorticoid-induced osteoporosis. J Bone Miner Res. 1989;4:137-141.

10. Dalle Carbonare L, Giannini S. Bone microarchitecture as an important determinant of bone strength. $J$ Endocrinol Invest. 2004;27:99-105.

11. Migliaccio S, Falcone S, Spera G. Bone modeling and remodeling: from biology to clinical application. Ageing Clin Exp Res. 2007;19S:5-10.

12. Weinstein RS, Jilka RL, Parfitt AM, Manolagas SC. Inhibition of osteoblastogenesis and promotion of apoptosis of osteoblasts and osteocytes by glucocorticoids. Potential mechanisms of their deleterious effects on bone. J Clin Invest. 1998;102:274-282.

13. O’Brien CA, Jia D, Plotkin LI, et al. Glucocorticoids act directly on osteoblasts and osteocytes to induce their apoptosis and reduce bone formation and strength. Endocrinology. 2004;145:1835-1841.

14. Heitzer MD, Wolf IM, Sanchez ER, Witchel SF, DeFranco DB. Glucocorticoid receptor physiology. Rev Endocr Metab Disord. 2007;8:321-330.

15. Bhargava A, Pearce D. Mechanisms of mineralcorticoid action: determinants of receptor specificity and actions of regulated gene products. Trends Endocrinol Metab. 2004;15:147-153.

16. Migliaccio S, Marino M. Estrogens and estrogen receptors: new actors in the plot of transcriptional regulation of genomic responses. Calcif Tissue Int. 2003;72:181-182.

17. Lipworth BJ. Therapeutic implications of non-genomic glucocorticoid activity. Lancet. 2000;356:87-89.

18. Plotkin LI, Manolagas SC, Bellido T. Glucocorticoids induce osteocyte apoptosis by blocking focal adhesion kinase-mediated survival Evidence for inside-out signaling leading to anoikis. $J$ Biol Chem 2007;282:24120-24130.

19. Beavan S, Horner A, Bord S, Ireland D, Compston J. Colocalization of glucocorticoid and mineralcorticoid receptors in human bone. $J$ Bone Miner Res. 2001;16:1496-1504.

20. Huang L, Xu J, Kumta SM, Zheng MH. Gene expression of glucocorticoid receptor $\alpha$ and $\beta$ in giant cell tumor of bone: evidence of glucocorticoid-stimulated osteoclastogenesis by stromal-like tumor cells. Mol Cell Endocrinol. 2001;181:199-206.

21. Wong MM, Rao LG, Ly H, Hamilton L, Tong J, Sturtridge W. Long-term effects of physiologic concentrations of dexamethasone on human bone-derived cells. J Bone Miner Res. 1990;5:803-813.

22. Beresford JN, Joyner CJ, Devlin C, Triffitt JT. The effects of dexamethasone and 1,25dihydroxyvitamin $\mathrm{D}_{3}$ on osteogenic differentiation of human bone marrow stromal cells in vitro. Arch Oral Biol. 1994;39:941-947.

23. Cheng SL, Yang JW, Rifas L, Zhang SF, Avioli LV. Differentiation of human bone marrow osteogenic stromal cells in vitro: induction of osteoblastic phenotype by dexamethasone. Endocrinology. 1994;134:277-286.
24. Cooper MS, Hewison M, Steward PM (1999) Glucocorticoid activity, inactivity and the osteoblast. J Endocrinol 163:159-164.

25. Delany AM, Gabbitas BY, Canalis E. Cortisol downregulates osteoblast $\alpha-1(\mathrm{I})$ procollagen mRNA by transcriptional and posttranscriptional mechanisms. J Cell Biochem. 1995;57:488-494.

26. Buxton EC, Yao W, Lane NE. Changes in serum receptor activator of nuclear factor-kappaB ligand, osteoprotegerin, and interleukin-6 levels in patients with glucocorticoid-induced osteoporosis treated with human parathyroid hormone (1-34). J Clin Endocrinol Metab. 2004;89:3332-3336

27. Leclerc N, Luppen CA, Ho VV, et al. Gene expression profiling of glucocorticoid-inhibited osteoblasts. J Mol Endocrinol. 2004; $33: 175-193$

28. Olkku A, Bodine PV, Linnala-Kankkunen A, Mahonen A. Glucocorticoids induce glutamine synthetase expression in human osteoblastic cells: a novel observation in bone. Bone. 2004;34:320-329.

29. Ohnaka K, Taniguchi H, Kawate H, Nawata H, Takayanagia R. Glucocorticoid enhances the expression of dickkopf-1 in human osteoblasts: novel mechanism of glucocorticoid-induced osteoporosis. Biochem Biophys Res Comm. 2004;318:259-264.

30. Van Staa TP, Leufkens HG, Abenhaim L, Zhang B, Cooper C, et al. Use of oral corticosteroids and risk of fractures. $J$ Bone Miner Res. 2000;15:993-1000.

31. Boling EP. Secondary osteoporosis: underlying disease and the risk for glucocorticoid-induced osteoporosis. Clin Ther. 2004;1:1-14.

32. Mazziotti G, Angeli A, Bilezikian JP, Canalis E, Giustina A. Glucocorticoid-induced osteoporosis: an update. Trends Endocrinol Metab. 2006;17:144-149.

33. Wallach S, Cohen S, Reid DM, et al. Effects of risedronate treatment on bone density and vertebral fracture in patients on corticosteroid therapy. Calcif Tissue Int. 2000;67:277-285.

34. Cosman F. Parathyroid hormone treatment for osteoporosis. Curr Opin Endocrinol Diabetes Obes. 2008;15:495-501.

35. Kaufman JM, Goemaere S. Osteoporosis in men. Best Pract Res Clin Endocrinol Metab. 2008;22:787-812.

36. Blick SD, Dhillon S, Keam SJ. Teriparatide: a review of its use in osteoporosis. Drugs. 2008;68:2709-2737.

37. Jilka RL. Molecular and cellular mechanisms of the anabolic effect of intermittent PTH. Bone. 2007;40:1434-1446.

38. Doggett TA, Swarthout JT, Jefcoat SC Jr, et al. Parathyroid hormone inhibits c-jun $\mathrm{N}$-terminal kinase activity in rat osteoblastic cells by a protein kinase A-dependent pathway. Endocrinology. 2002;143: $1880-1888$.

39. Sabatini M, Lesur C, Pacherie M, et al. Effects of parathyroid hormone and agonists of the adenylyl cyclase and protein kinase $\mathrm{C}$ pathways on bone cell proliferation. Bone. 1996;18:59-65.

40. Gesty-Palmer D, Chen M, Reiter E, et al. Distinct beta-arrestin and G-protein-dependent pathways for parathyroid hormone receptorstimulated ERK 1/2 activation. J Biol Chem. 2006;281:10856-10864.

41. Dobnig H, Turner RT. Evidence that intermittent treatment with parathyroid hormone increases bone formation in adult rats by activation of bone lining cells. Endocrinology. 1995;136:3632-3638.

42. Jilka RL, O'Brien CA, Ali AA, Roberson PK, Weinstein RS, Manolagas SC. Intermittent PTH stimulates periosteal bone formation by actions on post-mitotic preosteoblasts. Bone. 2008.

43. Jilka RL, Weinstein RS, Bellido T, Roberson P, Parfitt AM, Manolagas SC. Increased bone formation by prevention of osteoblast apoptosis with parathyroid hormone. J Clin Invest. 1999;104:439-446.

44. Wang BL, Dai CL, Quan JX, et al. Parathyroid hormone regulates osterix and Runx 2 mRNA expression predominantly through protein kinase A signaling in osteoblast-like cells. J Endocrinol Investig. 2006;29:101-108.

45. Datta NS, Pettway GJ, Chen C, Koh AJ, McCauley LK. Cyclin D1 as a target for the proliferative effects of PTH and PTHrP in early osteoblastic cells. J Bone mineral Res. 2007;22:951-964.

46. Canalis E, Giustina A, Bilezikian JP. Mechanisms of anabolic therapies for osteoporosis. N Engl J Med. 2007;357:905-916. 
47. Garrett IR. Anabolic agents and the bone morphogenetic protein pathway. Curr Dev Top Biol. 2007;78:127-171.

48. Kakar S, Einhorn TA, Vora S, et al. Enhanced chondrogenesis and Wnt signaling in PTH-treated fractures. J Bone Mineral Res. 2007;22: 1903-1912.

49. Kaback LA, Soung do Y, Naik A, et al. Teriparatide (1-34 human PTH) regulation of osterix during fracture repair. $J$ Cell Biochem. 2008; 105:219-226.

50. Bodine PV, Seestaller-Wehr L, Kharode YP, Bex FJ, Komm BS. Bone anabolic effects of parathyroid hormone are blunted by deletion of the Wnt antagonist secreted frizzled-related protein-1. J Cell Physiol. 2007;210:352-357.

51. Blalock SJ, Norton LL, Patel RA, Dooley MA. Patient knowledge, beliefs, and behavior concerning the prevention and treatment of glucocorticoidinduced osteoporosis. Arthritis Rheum. 2005;53:732-739.

52. van Staa TP, Leufkens HG, Abenhaim L, Begaud B, Zhang B, Cooper C. Use of oral corticosteroids in the United Kingdom. QJM. 2000;93:105-111.

53. Compston J. UK guidelines for glucocorticoid-induced osteoporosis: similarities and differences. Curr Rheumatol Rep. 2004;6:66-69.

54. Abadie EC, Devogealer JP, Ringe JD, et al. Recommendations for the registration of agents to be used in the prevention and treatment of glucocorticoid-induced osteoporosis: updated recommendations from the Group for the Respect of Ethics and Excellence in Science. Semin Arthritis Rheum. 2005;35:1-4.

55. Pereira RG, Delany AM, Canalis E. Effects of cortisol and bone morphogenetic protein-2 on stromal cell differentiation: correlation with CCAAT-enhancer binding protein expression. Bone. 2002;30:685-691.

56. Rosen CJ. What's new with PTH in osteoporosis: where are we and where are we headed? Trends Endocrinol Metab. 2004;15:229-33.

57. Seeman E. Reduced bone formation and increased bone resorption: rational targets for the treatment of osteoporosis. Osteoporos Int. 2003;14:S2-S8
58. Lane NE, Sanchez S, Genant HK, Jenkins DK, Arnaud CD. Short-term increases in bone turnover markers predict parathyroid hormone-induced spinal bone mineral density gains in postmenopausal women with glucocorticoid-induced osteoporosis. Osteoporosis Int. 2000;11:434-442.

59. Rehman Q, Lang TF, Arnaud CD, Modin GW, Lane NE. Daily treatment with parathyroid hormone is associated with an increase in vertebral cross-sectional area in postmenopausal women with glucocorticoidinduced osteoporosis. Osteop Int. 2003;14:77-81.

60. Saag KG, Shane E, Boonen S, et al. Teriparatide or alendronate in glucocorticoid-induced osteoporosis. N Engl J Med. 2007;357: 2028-2039.

61. Losada BR, Zanchetta JR, Zerbini C, et al. Active comparator trial of teriparatide vs alendronate for treating glucocorticoid-induced osteoporosis: results from Hispanic and non-hispanic cohorts. $J$ Clin Densitom. 2008.

62. Buxton EC, Yao W, Lane NE. Changes in serum receptor activator of nuclear factor-kappaB ligand, osteoprotegerin, and interleukin-6 levels in patients with glucocorticoid-induced osteoporosis treated with human parathyroid hormone (1-34). J Clin Endocrinol Metab. 2004;89:3332-336.

63. Lane NE, Sanchez S, Modin GW, Genant HK, Pierini E, Arnaud CD. Bone mass continues to increase at the hip after parathyroid hormone treatment is discontinued in glucocorticoid-induced osteoporosis: results of a randomized controlled clinical trial. J Bone Miner Res. 2000;15:944-951.

64. Saag K, Zanchetta J, Devogelaer J, Adler R, SeeK, Dalsky G. Teriparatide or alendronate in glucocorticoid-induced osteoporosis: data from 36 months trial. Annual Congress of the Am Soc Bone Mineral Res Abs. 2008;1171. 